\title{
The incidence of cardiovascular disease, cancer and type 2 diabetes comorbidities in HIV infection: A systematic review
}

\author{
Tilahun Nigatu $^{1}$, Brian Oldenburg ${ }^{1}$, Julian Elliott ${ }^{2}$, Geoffrey Setswe $^{3}$, Mulu Abraha Woldegiorgis ${ }^{4}$ \\ 1. Department of Epidemiology and Preventive Medicine, Monash University, Australia. 2. Infectious Disease Unit, Alfred \\ Hospital, Australia. 3. School of Health Sciences, Monash University, South Africa. 4. TSEHAl project, John Hopkins \\ University, Ethiopia.
}

Correspondence: Tilahun Nigatu. Address: Department of Epidemiology and Preventive Medicine, Monash University, Australia. Email: tilahu.haregu@monash.edu.

Received: August 26, 2012

DOI : $10.5430 /$ jnep.v3n7p58
Accepted: September 20, 2012

URL: http://dx.doi.org/10.5430/jnep.v3n7p58

\section{Abstract}

Introduction: Epidemiological linkages between HIV/AIDS and common Noncommunicable diseases are established. However, the incidence of these diseases among people living with HIV is not well examined.

Objectives: To describe the incidence of cardiovascular diseases, cancers, and type 2 diabetes among people living with HIV.

Methods: We have conducted a systematic review of incidence studies. Studies reporting on the incidence of cardiovascular diseases, cancers and type 2 diabetes among People living with HIV were retrieved from Embase and Medline databases. We used explicit eligibility and quality appraisal criteria to screen and select studies. We extracted study characteristics, outcome values and key conclusions. Findings were reported using tables and narrative summaries.

Results: A total of 30 studies were included in this systematic review. The incidence of cardiovascular diseases, cancers, and type 2 Diabetes comorbidities among people living with HIV was found to range from 1.19 to 11.3, 6.63 to 43.77, and 4.42 to 36.26 per 1000 person years, respectively. HIV infection was associated with increased risk of cardiovascular diseases and cancers. Specific types of antiretroviral drugs and longer duration of antiretroviral treatment were among the determinants of cardiovascular diseases and type 2 Diabetes in HIV infection. While the introduction of antiretroviral treatment was followed by a rapid decline in the incidence of AIDS-defining cancers, its effect on the incidence of non-AIDS defining cancers looks minimal.

Conclusion: The current evidence suggests that policies and interventions targeting people living with HIV should prioritize the prevention of the risk of common Noncommunicable diseases together with the rapid scale up of HIV treatment.

\section{Key words}

HIV-NCD comorbidity, Magnitude, Incidence 


\section{I ntroduction}

The epidemiological transition towards double-burden of diseases is expected to result in higher rates of comorbidity ${ }^{[1]}$. It is generally well understood that some infectious diseases are associated with increased risk of Non-communicable diseases (NCDs). On the other hand, NCDs predispose people to opportunistic infectious diseases ${ }^{[2]}$. Furthermore, some infectious diseases affect the risk of contracting other infectious diseases resulting in greater co-infection rates ${ }^{[3]}$. This also applies for NCDs. Hence, the relationships between and within disease categories are so complex but are worth considering. These complexities manifest as comorbidity.

There is no single agreed up on definition of comorbidity. Comorbidity may refer to diseases or disorders that exist together with an index disease; or it may refer to the co-occurrence of two or more diseases in an individual. Measurement of comorbidity has currently received more attention in medical research. Different data sources that are available to measure comorbidity include medical records, patient self-report, clinical judgment and administrative databases. Comorbidity can assume four major roles in statistical analysis: a confounder, an effect modifier, an exposure and an outcome. Most comorbidity studies involve the development and application of comorbidity indices to understand the effect of comorbidities on defined health outcomes ${ }^{[4-6]}$.

NCD comorbidity in HIV infection, the occurrence of an NCD in an individual with HIV, currently requires more attention along with the rapid emergence of NCDs as a major disease of public health importance in high HIV prevalent areas. Low-and-middle income countries which already have high magnitude of HIV are expected to share high burden of NCD comorbidity due to the associated increase in the incidence of NCDs ${ }^{[7]}$.

Though more is known about the clinical relationship between HIV and NCDs and the factors associated with their relationship, little is known about the epidemiology of their comorbidity. With the emergence of double mortality burden in low-and-middle income countries, better understanding of the epidemiology of HIV-NCD comorbidity is essential ${ }^{[8]}$. Data on the incidence and prevalence of common NCDs among people with HIV are available from different studies in different parts of the world. There are also several studies that have reported the effect of antiretroviral treatment on the risk of developing NCDs among people living with HIV (PLHIV). However, to the knowledge of the investigators, there is no research effort that summarizes the incidence of comorbidities of common NCDs in HIV infection.

Therefore, the aim of this study was to review and summarize the incidence of comorbidities of the cardiovascular diseases, cancers, and Diabetes and to describe the determinants of incidence of these comorbidities among people living with HIV.

\section{Methods}

\subsection{Search strategy and selection}

Studies reporting the incidence of cardiovascular disease, cancer and type 2 diabetes comorbidities among people living with HIV/AIDS were retrieved from Embase and Medline electronic databases. The key words used contain HIV/AIDS, one NCD term and incidence. The search was then filtered for cohort studies and registry matches only. References of review articles ${ }^{[9-12]}$ were also assessed to identify additional studies. The titles and abstracts of the resulting studies were reviewed for eligibility. The eligibility criteria used were: 1) Studies that report incidence of cardiovascular diseases (CVD), cancers or diabetes; 2) Studies mainly conducted on people living with HIV; and 3) published between 2000 and 2012. Studies that meet all these eligibility criteria were considered for review. 


\subsection{Appraisal of the studies}

We assessed all the eligible studies for the following appraisal criteria: 1) clearly defined cohort study design or registry match; 2) Sufficient sample size (more than 500 PLHIV); 3) Adequate follow up period (at least one year); 4) assessment at index visit and appropriate outcome ascertainment stated; and 5) explicitly stated comparison group including self (time- series) comparison. These criteria were rated on a dichotomous scale $(1=\mathrm{Yes}$ and $0=\mathrm{No})$. Studies that met all these criteria were included in the final review. In those cases where more than one study reported from the same cohort met the appraisal criteria, the most recent study was included.

\subsection{Data extraction}

We extracted relevant study and outcome characteristics using a standardized checklist. This checklist was pre-tested on 5 studies before application. Necessary amendments were made based on the results of the pre-test. The information extracted include name of first author, year of publication, study design, study population characteristics, follow up period, sample size for PLHIV, country of the study, number of new cases, total person-years of follow, incidence rates, associated risk factors, measures of association and major conclusion of the study. All these variables were double entered independently to ensure consistency of the extraction.

\subsection{Synthesis techniques}

Incidences of comorbidities were examined among studies within each NCD and among the three common NCDs. The findings were discussed based on the characteristics of the studies and the relative magnitude of the NCDs. Meta-analytic combination of findings was precluded by high level of heterogeneity among the studies. Even though confidence intervals of the incidence rates were recalculated from the available information, these were used for descriptive purpose only. For three studies person-years of follow up was estimated from average duration of follow up. Key findings of the studies that compared the incidence of the comorbidities of the three NCDs between 1) PLHIV (not on ART) versus HIV uninfected; 2) PLHIV (on ART) versus HIV uninfected; 3) PLHIV on ART versus PLHIV not on ART; and 4) PLHIV treatment groups (by type of drug and by duration of treatment) were also highlighted. Findings were reported using PRISMA guideline ${ }^{[13]}$.

\section{Results}

\subsection{Study characteristics}

The search strategy had resulted in a total of 533 studies. Ninety eight studies met the initial eligibility criteria. Full texts of these 98 studies were retrieved and reviewed. A total of 30 studies had met the quality appraisal criteria and were included in the final review (see Table 1).

Table 1. Number of studies addressing incidence of NCD comorbidities in HIV

\begin{tabular}{lllll}
\hline S\# & Type of NCD & Screened & Eligible & Included \\
\hline 1 & Cardiovascular disease & 274 & 22 & 10 \\
2 & Cancers & 176 & 50 & 14 \\
3 & Type 2 diabetes & 83 & 26 & 6 \\
& Total & $\mathbf{5 3 3}$ & $\mathbf{9 8}$ & $\mathbf{3 0}$ \\
\hline
\end{tabular}

The majority of the included studies were conducted in USA. All the included studies were conducted in the developed world, i.e. USA, Europe and Australia. Most of the studies that hadreported incidence of cancer was registry match studies while most of the studies that had reported incidences of CVD and Diabetes were prospective cohort studies. Most of the 
studies that had reported incidence of cancer were published between 2000 and 2005 while most of the studies that had reported the incidence of CVD and Diabetes were published after 2005.

\subsection{Cardiovascular diseases $(n=10)$}

A total of 186,867 people living with HIV were followed for about 705,772 person-years. During this follow up period a total of 1,654 new cases of cardiovascular disease were identified. From the included studies the incidence of CVD among PLHIV ranges from 1.19 to 11.13 per 1000 person-years of follow up (see Table 2).

Table 2. Cohort studies reporting the incidence of CVD among HIV infected people

\begin{tabular}{llllllll}
\hline Author & Year & $\begin{array}{l}\text { Follow up } \\
\text { period }\end{array}$ & PLHIV & $\begin{array}{l}\text { New CVD } \\
\text { cases }\end{array}$ & $\begin{array}{l}\text { Person } \\
\text { years }\end{array}$ & $\begin{array}{l}\text { Incidence }^{\#} \\
\text { (HIV+) }\end{array}$ & Country \\
\hline Lang S $^{[14]}$ & 2010 & $2000-2006$ & 74958 & 360 & 298156 & 1.24 & France \\
Triant VA $^{[15]}$ & 2007 & $1996-2004$ & 3851 & 189 & 16983 & 11.13 & US \\
Klein $^{[16]}$ & 2007 & $2000-2006$ & 6702 & 95 & 25200 & 2.40 & US \\
Holmberg $^{[17]}$ & 2002 & $1993-2002$ & 5672 & 21 & $17712^{*}$ & 1.19 & US \\
Mary-Krause $^{[18]}$ & 2003 & $1996-1999$ & 34956 & 60 & 88029 & 4.90 & France \\
Iloeje $^{[19]}$ & 2005 & $1996-2003$ & 7542 & 127 & $23765^{*}$ & 5.34 & US \\
SMART $^{[20]}$ & 2008 & $2004-2007$ & 2752 & 112 & $26047 *$ & 4.30 & UK, Den, AU. \\
Brothers $^{[21]}$ & 2009 & $1997-2004$ & 14174 & 43 & 11921 & 3.61 & US \\
Worm S $^{[22]}$ & 2010 & $1999-2007$ & 33308 & 580 & 178835 & 3.24 & US, EU, AU \\
Obel N $^{[23]}$ & 2010 & $1995-2005$ & 2952 & 67 & 19124 & 3.50 & Denmark \\
\hline
\end{tabular}

\#Per 1000 person years of follow up; *Estimated from average duration of follow up and incidence rates; US=United States; UK=United Kingdom; EU=Europe; AU=Australia

Studies included in this review indicated that HIV-positive people have increased risk of cardiovascular disease as compared to HIV-negative people. The risk of myocardial infarction among people living with HIV was about 1.5 times that of HIV negative people ${ }^{[14]}$. In comparison to other cardiovascular diseases, the relative risk of acute myocardial infarction was higher at about 1.75 times that of HIV-negative people ${ }^{[15]}$. The risk of coronary heart disease was also about 1.78 times more among PLHIV in late HAART ${ }^{[16]}$.

Studies had also indicated that the risk of CVD among PLHIV taking Antiretroviral treatment (ART) depends on the specific type of the Antiretroviral drug used. Holmberg et al had found that the hazard ratio of myocardial infarction among PLHIV who were taking Protease inhibitors was about 6.5 (95\% CI: 0·9-47-8) times as compared to its hazard ratio among those who were not taking protease inhibitors ${ }^{[17]}$. Compared to treatment naïve PLHIV, PLHIV taking Protease inhibitors had about $2.56(1.03,6.34)$ times more risk of myocardial infarction ${ }^{[18]}$. Although statistically significant, the findings from a study by Iloeje et al indicated modest level of risk of CVD associated with Protease inhibitor use, a Hazard ration of $1.71(1.08,2.74)$ as compared to Non-Protease inhibitor users ${ }^{[19]}$. PLHIV taking abacavir containing ART were about 2 times at a higher risk of CVD as compared to those taking other regimens that do not containing this drug ${ }^{[20]}$. However, the study by Brothers et al reported no supportive evidence of increased risk of CVD among Abacavir users ${ }^{\text {[21] }}$.

Other studies from the D: A: D cohort indicated that both Abacavir and Didanosine use were associated with about 2 times increased risk of Myocardial infarction as compared to other antiretroviral drugs ${ }^{[24]}$. From the same cohort, it was reported that the duration of exposure to ART was also a factor for increased risk of CVD. A study from D: A: D showed that ART was independently associated with a 26\% relative increase in the rate of Myocardial Infarction per year of exposure during the first four to six years of its use ${ }^{[25]}$. 


\subsection{Cancers $(n=14)$}

Fourteen studies that had reported the incidence of cancers among PLHIV were reviewed. Most of the studies used registry match as their major method of identifying HIV cases with cancer. The others were prospective cohort studies. The incidence rate of cancer ranged from 6.63 to 43.77 per 1000 person years of follow up. Overall, 84,374 cancers were reported in 3,422,910 person years of follow up. The majority (81.4\%) of these were AIDS defining cancers (ADC). The rest 18.6\% were non-AIDS defining cancers (NADC). High variations of among incidence rates were observed (see Table 3).

Table 3. Incidence rates of cancer (all types) per 1000 person years of follow up

\begin{tabular}{lllllllll}
\hline Author (Ref) & Year & Follow up & PLHIV & $\begin{array}{l}\text { Person } \\
\text { years }\end{array}$ & $\begin{array}{l}\text { Incidence } \\
\text { (ADC) }\end{array}$ & $\begin{array}{l}\text { Incidence } \\
\text { (NADC) }\end{array}$ & $\begin{array}{l}\text { Incidenc } \\
\text { e (All) }\end{array}$ & Country \\
\hline Frisch $^{[26]}$ & 2001 & $1980-1996$ & 302834 & 1438462 & 21.45 & 3.07 & 24.52 & US \\
Glurich $^{[27]}$ & 2002 & $1985-1999$ & 13067 & 77114 & 5.72 & 2.54 & 8.26 & Australia \\
Allardice $^{[28]}$ & 2003 & $1981-1996$ & 2754 & 15913 & 8.67 & 1.51 & 10.18 & Scotland \\
Dal Maso $^{[29]}$ & 2003 & $1985-1998$ & 12104 & 60421 & 16.42 & 2.81 & 19.23 & Italy \\
Clifford $^{[30] *}$ & 2005 & $1985-2002$ & 7304 & 28836 & 17.06 & 4.58 & 21.64 & Switzerland \\
Newnham $^{[31]}$ & 2005 & $1985-2001$ & 33190 & 189758 & 8.33 & 2.33 & 10.66 & UK \\
Engels $^{[32]}$ & 2006 & $1980-2002$ & 317428 & 477368 & 39.68 & 3.41 & 43.09 & US \\
Mbulaiteye $^{[33]}$ & 2003 & $1990-1996$ & 82217 & 107728 & 40.44 & 3.33 & 43.77 & US \\
Guiquet $^{[34] *}$ & 2009 & $1998-2006$ & 52278 & 255353 & 4.21 & 2.42 & 6.63 & France \\
Patel $^{[35]_{*}}$ & 2008 & $1992-2003$ & 54780 & 157819 & 4.49 & 18.01 & 22.49 & US \\
Seaberg $^{[36] *}$ & 2010 & $1984-2004$ & 2940 & 32383 & 23.28 & 2.87 & 26.16 & US \\
Glaceran $^{[37]}$ & 2007 & $1981-1999$ & 1659 & 7050 & 24.26 & 2.98 & 27.24 & Spain \\
Bedimo $^{[38] *}$ & 2004 & $1989-2002$ & 2882 & 7452 & 23.89 & 6.58 & 30.46 & US \\
Gallagher $^{[39]}$ & 2001 & $1981-1994$ & 122993 & 567254 & 14.13 & 8.25 & 22.39 & US \\
\hline
\end{tabular}

*prospective cohort studies

The overall relative risk of NADC cancer was 2.7 (95\% CI: 2.7-2.8) in Frisch et al study. But the incidence of NADC didn't appear to be influenced by advanced imunosupression associated with HIV disease progression ${ }^{[26]}$. People with HIV who are only mildly immune deficient may not be at increased risk of NADC ${ }^{[27]}$. A study by Allardice et al, conducted before ART become widely available, had reported Standardized incidence ratio (SIR) of 10.8 (95\% CI: 9.2-12.6) for all cancers. The SIR for NADC in this study was 1.8 (95\% CI: 1.1-2.6) ${ }^{[28]}$. Another study conducted in Italy had reported SIR of 2.3 (95\% CI: 2.0-2.7) for NADC. Anal cancer, lung cancer and brain tumours were among those NADCs with the highest SIR ${ }^{[29]}$.

A study that examined the influence of behavioral risk factors and ART on the risk of cancer using data from the Swiss HIV cohort study didn't find any cancers of lip, mouth, pharynx and lung among non-smokers. This study had also suggested that ART may not prevent the risk of NADC ${ }^{[30]}$. A study conducted in Southeast England reported SIR of 2.8(95\% CI: 2.6-3.1) for NADC. In this study men were at a higher risk of cancer ${ }^{[31]}$. A study that had investigated the effect of ART on cancer trend in US indicated that ART was associated with a dramatic decline in Kaposis Sarcoma and Non-Hodgkin Lymphoma. The risk of cervical cancer didn't change with ART. Decline in risk of lung cancer but an increase in risk of Hodgkin lymphoma was observed. No overall change in risk of NADC was associated with ART ${ }^{\text {[32] }}$

A study that examined the relationship between cancer risk and AIDS-related immunosupression (as measured by CD4 count at AIDS onset) had illustrated that the risks of Kaposis Sarcoma and Non-Hodgkin Lymphoma were positively associated with CD4 count. However, the risks of cervical cancer and NADCs were not related to CD4 counts, suggesting 
that increased risks of NADCs may be a result of lifestyle factors ${ }^{[33]}$. A prospective cohort study from France had also indicated that ART might be more beneficial the reducing the risk of cancer if it can restore or maintains CD4 count above 500 cells per micro litre, thereby indicating the need for an earlier diagnosis of HIV infection and an earlier treatment initiation ${ }^{[34]}$.

A study on the incidence of cancer among HIV infected people as compared to the general population in the US reported that the incidence of many NADCs was higher among HIV infected persons ${ }^{[35]}$. In the multicentre AIDS cohort study among men, the incidence of Kaposis Sarcoma and Non-Hodgkin lymphoma has decreased while the incidence of anal cancer has increased in the HAART era as compared to the pre-HAART era ${ }^{[36]}$. Increased risks of Hodgkin's lymphoma, liver cancer, lung cancer, and in situ cervical cancer among AIDS patients were also reported by a study conducted in Spain ${ }^{[37]}$. A longer duration of survival during the HAART era was proposed to be one of the explanations for increased risk of NADC among PLHIV ${ }^{[38]}$.

Elevated risks of Hodgkin's disease; cancer of rectal area, respiratory tract, brain and central nervous system were found in a study of AIDS patients in New York State. Increasing trends of increase relative risks from the pre-AIDS to the postAIDS period were observed for cancers of the rectal and anal area, respiratory tract, skin, and connective tissues among men and invasive cervical cancer in women ${ }^{[39]}$.

\subsection{Diabetes $(n=6)$}

Six prospective cohort studies that measured the incidence of diabetes among people living with HIV were included in this review. Three of these studies recruited PLHIV receiving treatment, treatment naive PLHIV and HIV-negative people in the follow up. One study recruited PLHIV receiving treatment and treatment naive PLHIV only. The rest three studies had focused on PLHIV taking ART only.

Over a total of 175,202 person-years of follow up 1,178 of the 44,484 HIV positive persons developed type 2 diabetes. The incidence of diabetes ranged from 4.42 cases per 1000 person years in Swiss HIV cohort study to 36.26 cases per 1000 person years in the multicenter AIDS cohort study. A study from the D: A: D cohort which had the highest number of study participants and person years of follow up had reported an incidence of 5.72 per 1000 person years (see Table 4).

Table 4. Incidence of Diabetes among PLHIV in the seven prospective cohort studies

\begin{tabular}{|c|c|c|c|c|c|c|c|}
\hline Author & Year & $\begin{array}{l}\text { Follow up } \\
\text { period }\end{array}$ & $\begin{array}{l}\text { Number of } \\
\text { HIV+ }\end{array}$ & $\begin{array}{l}\text { New DM } \\
\text { cases }\end{array}$ & $\begin{array}{l}\text { Person } \\
\text { years }\end{array}$ & $\begin{array}{l}\begin{array}{l}\text { Incidenceb }^{\#} \\
(\mathrm{HIV}+)\end{array} \\
\end{array}$ & 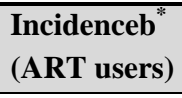 \\
\hline Capeau $^{[40]}$ & 2012 & $2000-2009$ & 1,046 & 111 & 7,846 & 14.18 & 14.18 \\
\hline De Witt ${ }^{[41]}$ & 2008 & 1999-2006 & 33,398 & 744 & 130,151 & 5.72 & 5.72 \\
\hline Justman $^{[42]}$ & 2003 & 1994-1999 & 1,435 & 56 & 3,673 & 15.25 & 17.33 \\
\hline Brown $^{[43]}$ & 2005 & 1999-2003 & 568 & 28 & 772.1 & 36.26 & 47.17 \\
\hline Ledergerber ${ }^{[44]}$ & 2007 & 2000-2006 & 6,513 & 123 & 27,798 & 4.42 & 4.99 \\
\hline Tein $^{[45]}$ & 2007 & 2000-2006 & 1,524 & 116 & 4,962 & 23.37 & 27.36 \\
\hline
\end{tabular}

\#Studies conducted on ART users only

*Incidence per 1000 person-years of follow up

Older age and adiposity were linked with higher risk of diabetes among PLHIV who had started on combination antiretroviral treatment at French clinical sites ${ }^{[40]}$. The use of two thymidine analogs (Stavudine and Zidovudine) was significantly associated with diabetes after the adjustment of potential confounders in a study reported from D: A: D cohort. In the same study, the incidence of diabetes was found to increase with cumulative exposure to combination antiretroviral treatment after adjustment for potential risk factors of diabetes ${ }^{[41]}$. 
Protease inhibitors use was found to be associated with a three-fold increase in the risk incident diabetes. Age and body mass index were also important predictors of risk of diabetes among PLHIV ${ }^{[42]}$. In the Muticenter AIDS cohort study, the relative risk of diabetes among HIV infected men taking HAART was more than four times that of HIV sero-negative men after adjustment for age and body mass index ${ }^{[43]}$.

In a study reported from the Swiss HIV cohort, traditional risk factors, and current treatment with protease inhibitor- and nucleoside-reverse transcriptase- containing regimens were associated with risk of type 2 diabetes mellitus ${ }^{[44]}$.

In the women's interagency HIV cohort study, there was 1.4 fold increased incidence of diabetes in HIV infected women as compared to HIV negative women, but the difference was not statistically significant. This study had also reported a relative hazard of 2.64 [95\% CI: 1.11-6.32] for the risk of diabetes among PLHIV who were exposed to Nucleoside reverse transcriptase for more than three years suggesting that longer exposure to Nucleoside reverse transcriptase inhibitors may increase risk of diabetes ${ }^{[45]}$.

\section{Discussion}

The incidence of CVD as reported by the studies included in this review was between 2.24 and 5.34 per 1000 person years except for one study which reported an incidence of 11.3 per 1000 person years and two studies which have reported incidence rates below 1.5 per 1000 person years. The higher incidence in Traint VA et al study could be due to the recruitment of older patients from a higher risk background population in tertiary hospitals ${ }^{[15]}$. The incidence of CVD was relatively low in the two studies due to the low level of incidence of the problem in the background population ${ }^{[14,17]}$.

The findings support the notion that HIV infection is generally associated with increased risk of cardiovascular disease. They are also in favor of the importance of antiretroviral treatment in decreasing the risk of cardiovascular diseases. However, the use of specific antiretroviral drugs is found to be associated with a higher risk of cardiovascular disease as compared to the use of other antiretroviral drugs.

The incidence of cancers was highly variable among the studies. The SIR of ADCs was very high while that of NADC was modest. Antiretroviral treatment was associated with a rapid decline in the incidence of ADCs. However, the effect of ART on the incidence of NADCs seems low. In some cases an increasing trend of NADC was observed among PLHIV receiving ART (36). Several body parts were found to be affected by NADCs. Longer survival and the role of traditional risk factors were also found to be more important.

The two largest studies reported the incidence of type 2 Diabetes among PLHIV to be 5.72 and 4.42 per 1000 person years ${ }^{[41,44]}$. The other studies have reported incidence rates of greater than 14 per 1000 person years. The risk of diabetes associated with antiretroviral use also varied by the type of the drugs considered. Protease inhibitors are associated with about 3 times increased risk of diabetes as compared to other types of drugs. Nucleoside reverse transcriptase inhibitors such as Stavudine, Didanosine, Zidovudine and Indinavir are also associated with increased risk of diabetes.

\section{Limitations}

We have encountered higher level of heterogeneity among the characteristics and outcomes of the included studies during the review. This had effect on the overall interpretation of the findings of the study. Besides, the number of studies that met the inclusion criteria for type 2 diabetes was low. The review had also looked in to cardiovascular and cancers in general terms and specific types of cardiovascular diseases and cancers are not well addressed by this review. Moreover, all the included studies were from the developed world and could not reflect the magnitude and determinants of major NCDs in high HIV prevalent areas of the developing world like Sub-Saharan Africa. 


\section{Conclusions}

The current evidence suggests that cardiovascular diseases, cancers and type 2 Diabetes are important comorbidities of HIV infection. Policies and interventions targeting people living with HIV should prioritize the prevention of the risk of common Noncommunicable diseases along with the rapid scale up of HIV treatment. Integrated provision of HIV and NCD services for PLHIV could maximize synergy and improve efficiency.

\section{References}

[1] Young F, et al. A review of co-morbidity between infectious and chronic disease in Sub-Saharan Africa: TB and Diabetes Mellitus, HIV and Metabolic Syndrome, and the impact of globalization. Globalization and Health. 2009; 5: 9. PMid:19751503 http://dx.doi.org/10.1186/1744-8603-5-9

[2] Stevenson et al. Diabetes and tuberculosis: the impact of the diabetes epidemic on tuberculosis incidence. BMC Public Health. 2007; 7: 234. PMid:17822539 http://dx.doi.org/10.1186/1471-2458-7-234

[3] World Health Organization. Priority research questions for TB/HIV in HIV prevalent and Resource limited settings. 2010, Switzerland.

[4] De Groot V, Beckerman H, Lankhorst GJ, Bouter LM. How to measure comorbidity: A critical review of available methods. Journal of Clinical Epidemiology. 2003; 56: 221-229. http://dx.doi.org/10.1016/S0895-4356(02)00585-1

[5] Lash TL, et al. Methodology, Design and Analytic techniques to address measurement of comorbid disease. J Gerontol A Biol Sci Med Sci. 2007; 62(3): 281-285. PMid:17389725 http://dx.doi.org/10.1093/gerona/62.3.281

[6] Hall SF. A user's guide to selecting a comorbidity index for clinical research. Journal of Clinical Epidemiology. 2006 ; 59: 849-855. PMid:16828679 http://dx.doi.org/10.1016/j.jclinepi.2005.11.013

[7] IDF, Uicc, World Heart Federation. Time to act: The Global Emergency of Noncommunicable diseases. Report on 'Health development: Held back by Noncommunicable diseases'. 2009

[8] Misganaw A, Mariam DH, Araya T. The double mortality burden among adults in Addis Ababa, Ethiopia, 2006-2009. Prev Chronic Dis. 2012; 9: 110142.

[9] Islam FM, Wu J, Jansson J, WilsonDP. Relative risk of cardiovascular disease among people living with HIV: a systematic review and meta-analysis. HIV Medicine. 2012. http://dx.doi.org/10.1111/j.1468-1293.2012.00996.x

[10] Manfredi R, Calza L. The risk of myocardial infarction during HIV infection treated with antiretroviral combinations. Revista Latinoamericana de Hipertensión. 2009; 4(4).

[11] Grulich AE, Van Leeuwen MT, Falster MO, Vajdic CM. Incidence of cancers in people with HIV/AIDS compared with immunosuppressed transplant recipients: a meta-analysis. Lancet. 2007; 370: 59-67. http://dx.doi.org/10.1016/S0140-6736(07)61050-2

[12] Das S. Insulin resistance and Diabetes in HIV infection. Recent Patents on Anti-Infective Drug Discovery. $2011 ; 6:$ 260-268. http://dx.doi.org/10.2174/157489111796887846

[13] Liberati A, Altman DG, Tetzlaff J, Mulrow C, Gøtzsche PC, et al. The PRISMA Statement for Reporting Systematic Reviews and Meta-Analyses of Studies That Evaluate Health Care Interventions: Explanation and Elaboration. PLoS Med. 2009; 6(7): e1000100. PMid:19621070 http://dx.doi.org/10.1371/journal.pmed.1000100

[14] Lang S, Mary-krause M, Gilquin LCJ, Partisan M, Boccar ASF, Bingham A, et al. Increased risk of myocardial infarction in HIV-infected patients in France, relative to the general population. AIDS. 2010; 24:1221-1230. PMid:20400883 http://dx.doi.org/10.1097/QAD.0b013e328339192f

[15] Triant VA, Lee H, Hadigan C, Grinspoon SK. Increased Acute Myocardial Infarction Rates and Cardiovascular Risk Factors among Patients with Human Immunodeficiency Virus Disease. The Journal of Clinical Endocrinology \& Metabolism. 2006; 92(7): 2506-2512. PMid:17456578 http://dx.doi.org/10.1210/jc.2006-2190

[16] Klein D, Hurley L, Silverberg M, Horberg M, Queensberry C, Sidney S. Surveillance Data for MI Hospitalizations among HIV+ and HIV- Northern Californians: 1994-2006. Abstract number 807. 14th Conference on retroviruses and opportunistic infections.

[17] Holmberg SD, Moorman AC, Williamson JM, Tong TC, Ward DJ, Wood KC. Protease inhibitors and cardiovascular outcomes in patients with HIV-1. Lancet. 2002; 360: 1747-48. http://dx.doi.org/10.1016/S0140-6736(02)11672-2

[18] Mary-Krause M, Cotte Lb, Simon A, Partisani M, Costagliola D, the Clinical Epidemiology Group from the French Hospital Database. Increased risk of myocardial infarction with duration of protease inhibitor therapy in HIV-infected men. AIDS. 2003; 17: 2479-2486. PMid:14600519 http://dx.doi.org/10.1097/00002030-200311210-00010 
[19] UH Iloeje UH, Yuan Y, L’Italien G, Mauskopf J, Holmberg SD, Moorman AC, et al. Protease inhibitor exposure and increased risk of cardiovascular disease in HIV-infected patients. HIV Medicine. 2005; 6: 37-44. PMid:15670251 http://dx.doi.org/10.1111/j.1468-1293.2005.00265.x

[20] The SMART/INSIGHT and the D:A:D study groups. Use of nucleoside reverse transcriptase inhibitors and risk of myocardial infarction in HIV-infected patients. AIDS. 2008; 22(14): F17-F24. PMid:18753925 http://dx.doi.org/10.1097/QAD.0b013e32830fe35e

[21] Brothers CH, Hernandez JE, Cutrell AG, Curtis L, Ait-Khaled M, Bowlin SJ, et al. Risk of Myocardial Infarction and Abacavir Therapy: No Increased Risk Across 52 GlaxoSmithKline-Sponsored Clinical Trials in Adult Subjects. J Acquir Immune Defic Syndr. 2009; 51: 20-28. PMid:19282778 http://dx.doi.org/10.1097/QAI.0b013e31819ff0e6

[22] Worm S, Sabin C, Weber R, Reiss P, El-Sadr W, Dabis F, et al. Risk of Myocardial Infarction in Patients with HIV Infection Exposed to Specific Individual Antiretroviral Drugs from the 3 Major Drug Classes: The Data Collection on Adverse Events of Anti-HIV Drugs (D:A:D) Study. The Journal of Infectious Diseases. 2010; 201: 000-000

[23] Obel N, Farkas DK, Kronborg G, Larsen CS, Pedersen G, Riis A, et al. Abacavir and risk of myocardial infarction in HIV-infected patients on highly active antiretroviral therapy: a population-based nationwide cohort study. HIV Medicine. 2010; 11: 130-136. PMid:19682101 http://dx.doi.org/10.1111/j.1468-1293.2009.00751.x

[24] D:A:D Study Group. Use of nucleoside reverse transcriptase inhibitors and risk of myocardial infarction in HIV-infected patients enrolled in the D:A:D study: a multi-cohort collaboration. Lancet. 2008; 371: 1417-26. http://dx.doi.org/10.1016/S0140-6736(08)60423-7

[25] The Data Collection on Adverse Events of Anti-HIV Drugs (DAD) Study Group. Combination Antiretroviral Therapy and the Risk of Myocardial Infarction. N Engl J Med. 2003; 349: 1993-2003. PMid:14627784 http://dx.doi.org/10.1056/NEJMoa030218

[26] Frisch M, Biggar RJ, Engels EA, Goedert JJ, AIDS-cancer match registry study group. Association of cancer with AIDS related immunosupression in adults. JAMA. 2001; 285(13): 1736-1745. PMid:11277828 http://dx.doi.org/10.1001/jama.285.13.1736

[27] Grulich AE, Li Y, McDonald A, Correll PKL, Law MG, Kaldor JM. Rates of non-AIDS-defining cancers in people with HIV infection before and after AIDS diagnosis. AIDS. 2002; 16: 1155 \pm 1161 .

[28] Allardice GM, Hole DJ, Brewster DH, Boyd J, Goldberg DJ. Incidence of malignant neoplasms among HIV-infected persons in Scotland. British Journal of Cancer. 2003; 89: 505-507. PMid:12888821 http://dx.doi.org/10.1038/sj.bjc.6601139

[29] Dal Maso L, Franceschi S, Polesel J, Braga C, Piselli P, Crocetti E, et al. Risk of cancer in persons with AIDS in Italy, $1985-1998$. British Journal of Cancer. 2003; 89: 94-100. PMid:12838307 http://dx.doi.org/10.1038/sj.bjc.6601017

[30] Clifford GM , Polesel J , Rickenbach M on behalf of the Swiss HIV Cohort Study , Dal Maso L , Keiser O, Andreas K, et al. Cancer Risk in the Swiss HIV Cohort Study: Associations With Immunodefi ciency, Smoking, and Highly Active Antiretroviral Therapy. J Natl Cancer Inst. 2005; 97: 425-32. PMid:15770006 http://dx.doi.org/10.1093/jnci/dji072

[31] Newnham A, Harris J, Evans HS, Evans BG, Møller H. The risk of cancer in HIV-infected people in southeast England: a cohort study. British Journal of Cancer. 2005; 92: 194-200. PMid:15583689 http://dx.doi.org/10.1038/sj.bjc.6602273

[32] Engels EA, Pfeiffer RM, Goedert JJ, Virgo P, McNeel TS, Scoppa SM. Trends in cancer risk among people with AIDS in the United States 1980-2002. AIDS. 2006; 20: 1645-1654. PMid:16868446 http://dx.doi.org/10.1097/01.aids.0000238411.75324.59

[33] Mbulaiteye SM, Biggar RJ, Goedert JJ, Engels EA. Immune Deficiency and Risk for Malignancy Among Persons with AIDS. JAIDS. 2003; 32: 527-533. PMid:12679705 http://dx.doi.org/10.1097/00126334-200304150-00010

[34] Guiguet M, Boué F, Cadranel J, Lang JM, Rosenthal E, Costagliola D, et al. Eff ect of immunodefi ciency, HIV viral load, and antiretroviral therapy on the risk of individual malignancies (FHDH-ANRS CO4): a prospective cohort study. Lancet Oncol. 2009; 10: 1152-59. http://dx.doi.org/10.1016/S1470-2045(09)70282-7

[35] Patel P, Hanson DL, Sullivan PS, Novak RM, Moorman AC, Tong TC, et al. Incidence of Types of Cancer among HIV-Infected Persons Compared with the General Population in the United States, 1992-2003. Ann Intern Med. 2008; 148: $728-736$. PMid:18490686

[36] Seaberg EC, Wiley D, Martı́nez-Maza O, Chmiel OS, Kingsley L, Tang Y, et al. Cancer Incidence in the Multicenter AIDS Cohort Study Before and During the HAART Era. Cancer. 2010; 5507-5516. PMid:20672354 http://dx.doi.org/10.1002/cncr.25530

[37] Galceran J, Marcos-Gragera R, Maria Soler M, Romaguera A, Ameijide A, Izquierdo A, et al. Cancer incidence in AIDS patients in Catalonia, Spain. European Journal of cancer. 2007; 43: 1085-1091. PMid:17349785 http://dx.doi.org/10.1016/j.ejca.2007.01.028

[38] Bedimo R, Chen RY, Accortt NA, Raper JL, Linn C, Allison JJ, et al. Trends in AIDS-Defining and Non-AIDS-Defining Malignancies among HIV-Infected Patients: 1989-2002. Clinical Infectious Diseases. 2004; 39: 1380-4. PMid:15494916 http://dx.doi.org/10.1086/424883

[39] Gallagher B, Wang Z, Schymura MJ, Kahn A, Fordyce EJ. Cancer Incidence in New York State Acquired Immunodeficiency Syndrome Patients. Am J Epidemiol. 2001; 154: 544-56. PMid:11549560 http://dx.doi.org/10.1093/aje/154.6.544 
[40] Capeau J, Bouteloup V, Katlama C, Bastard JP, Guiyedi V, Salmon-Ceron D, et al. Ten-year diabetes incidence in 1046 HIV-infected patients started on a combination antiretroviral treatment. AIDS. 2012 Jan 28; 26(3): 303-14. PMid:22089377 http://dx.doi.org/10.1097/QAD.0b013e32834e8776

[41] De Wit S, Sabin CA, Weber R, Worm SW, Reiss P, Cazanave C, et al. Incidence and risk factors for new-onset diabetes in HIV-infected patients: the data collection on adverse effects of anti-HIV drugs (D:A:D) study. Diabetes Care. 2008; 31(6): 1224-1229. PMid:18268071 http://dx.doi.org/10.2337/dc07-2013

[42] Justman JE, Benning L, Danoff A, Minkoff H, Levine A, Greenblatt RM, et al. Protease inhibitor use and the incidence of diabetes mellitus in a large cohort of HIV-infected women. J Acquir Immune Defic Syndr. 2003; 32(3): 298-302. PMid:12626890 http://dx.doi.org/10.1097/00126334-200303010-00009

[43] Brown TT, Coles SR, Li X, Kingsley LA, Palella FJ, Riddler SA, et al. Antiretroviral therapy and the prevalence and incidence of Diabetes mellitus in the multicenter AIDS cohort study. Arch Intern Med. 2005; 165: 1179-1184. PMid:15911733 http://dx.doi.org/10.1001/archinte.165.10.1179

[44] Ledergerber B, Furrer H, Rickenbach M, Lehmann R, Elzi L, Hirschel B, et al. Factors associated with the incidence of type 2 diabetes mellitus in HIV-infected participants in the Swiss HIV Cohort Study. Clin Infect Dis. Jul 1 2007; 45(1): 111-119. PMid:17554711 http://dx.doi.org/10.1086/518619

[45] Tien PC, Schneider MF, Cole SR, Levine AM, Cohen M, DeHovitz J, et al. Antiretroviral therapy exposure and incidence of diabetes mellitus in the Women's Interagency HIV Study. AIDS. 2007 Aug 20; 21(13): 1739-1745. PMid:17690572 http://dx.doi.org/10.1097/QAD.0b013e32827038d0 